HELSINGIN YLIOPISTO

HELSINGFORS UNIVERSITET

UNIVERSITY OF HELSINKI 


\title{
Compulsory school achievement and gambling among men and women aged 18-29 in Finland
}

\author{
TIINA LATVALA ${ }^{1,2}$, SARI CASTR N 1,3,4, HANNU ALHO ${ }^{3,5} \&$ ANNE SALONEN 1,3
}

${ }^{1} \mathrm{~A}$ Icohol, drugs and addictions unit, D epartment of Public $\mathrm{H}$ ealth Solutions, $\mathrm{N}$ ational Institute for $\mathrm{H}$ ealth and W elfare, F inland, ${ }^{2} T$ he $F$ innish F oundation for A Icohol Studies, Finland, $3 /$ nstitute of Clinical M edicine, U niversity and U niversity $\mathrm{H}$ ospital of $\mathrm{H}$ elsinki, $\mathrm{F}$ inland, ${ }^{4} \mathrm{D}$ epartment of $\mathrm{P}$ sychology and Speech $\mathrm{L}$ anguage $\mathrm{P}$ athology, $U$ niversity of T urku, F inland, and ${ }^{5} \mathrm{~A}$ bdominal $\mathrm{C}$ entre, U niversity and $\mathrm{U}$ niversity $\mathrm{H}$ ospital of $\mathrm{H}$ elsinki, Finland

\begin{abstract}
A ims: T his study aims to explore the associations between final compulsory school grades and gambling and their relation to substance use and perceived mental health among people aged 1829 in Finland $(N=831)$. M ethods: C ross-sectional random sample data, weighted on the basis of age, gender and region of residence, were collected in 2015.T he data were analysed using logistic regression models adjusted for sociodemographic variables, risky alcohol use, daily smoking, and perceived mental health. Results: Weekly gambling and at-risk and problem gambling (ARPG) were more common among men. Weekly gambling was linked to smoking and risky alcohol use among men and smoking among women. Additionally, ARPG was linked to risky alcohol use among men. ARPG was associated with moderate/poor mental health among men and women, but this was not the case with weekly gambling. Among men, low and average final school grades at age 16 were associated with weekly gambling later in life, even when adjusting for other variables. Among women, low and average final school grades were not associated with weekly gambling when adjusting for substance use. L ower final school grades were associated with ARPG among women but not among men when all potential confounders were adjusted for. Conclusions: Adolescents with lower final school grades are more likely to gamble weekly later in life Lower final school grades are also linked with ARPG among women. It is important therefore for schools to haveclear policies on gambling and to implement early prevention programmes.
\end{abstract}

KeyWords: A t-risk and problem gambling, gender, population survey, register data, school achievement, weekly gambling

\section{Introduction}

Low school achievement predisposes young people to gambling and other risk behaviours and has a detrimental effect on their later life path [1]. At-risk and problem gambling (ARPG) is a growing public health concern in many countries [2], causing significant harm for some gamblers, their families and the community. Participation in gambling is at its peak during emerging adulthood, when rates for problem gambling are often higher than in older adults $[3,4]$. This period of life is furthermore often characterized by a high prevalence of many other types of risky behaviours [5], such as alcohol use and smoking.
ARPG refers to a wide spectrum of problematic gambling [6]. The prevalence of ARPG is higher among men than women, and overall participation in gambling is also more common among men $[7,8]$. $\mathrm{H}$ aving said that, there is growing evidence, both nationally [4] and internationally [9], that gambling among women is on the increase. There is also evidence that individuals with lower socioeconomic status are at higher risk of problem gambling [10]. For example, lower income receivers have been found to gamble more than those with a higher income [11]. Women tend to have lower income than men the

C orrespondence: T iina L atvala, $\mathrm{N}$ ational Institute for $\mathrm{H}$ ealth and W elfare, D epartment of Public $\mathrm{H}$ ealth Solutions, The Alcohol, D rugs and Addictions U nit, P.O. Box 30, FI-00271, H elsinki, Finland. E-mail: tiina.rasanen@thl.fi

D ate received 23 M arch 2017; reviewed 29 J une 2017; accepted 13 J uly 2017

' Author(s) 2017

Reprints and permissions: sagepub.co.uk/journalsPermissions. nav

DOI: $10.1177 / 1403494817726621$

journals.sagepub.com/home/sjp 
difference in Finland is around 20\% [12] which may put women at greater risk of gambling [13].

Both ARPG and weekly gambling may be associated with harmful behaviours such as smoking and alcohol misuse, as well as with depression [7]. Some studies have shown gender differences in associations between gambling, depression and risk-taking behaviours $[14,15]$, men being more at risk. There is also evidence of a gender difference in $G$ rade Point Averages (GPAs) in the Finnish education system, with girls more frequently scoring higher GPAs than boys [16].

$R$ isk behaviours, which are known to affect school achievement $[1,17,18]$, can compromise successful transition from adolescence to adulthood, and eventually lead to unemployment, lower income and various health and mental problems [16]. Low school achievement can lead to gambling or vice versa the direction of this association is unclear, but two previous studies $[17,18]$ imply that poor school achievement is a link to gambling problems.

Previous studies on the associations between gambling and school achievement have concentrated on ARPG or problem gambling only, ignoring weekly gambling. $G$ ender differences are often disregarded as well, despite evidence of significant differences between men and women in gambling and other risk behaviours [ 7,15$]$. F urthermore, with just one exception [17], most earlier studies have used self-reported measurements of school achievement. For purposes of prevention and policymaking it is of utmost importance to identify and examine factors that may be associated with the later development of gambling problems, such as school achievement. It is equally important to explore and understand the gender differences in these associations so that we can develop more gender-sensitive prevention and intervention programmes.

This study uses epidemiological data to 1 ) explore gambling (weekly gambling, ARPG) in relation to substance use (risky alcohol use, daily smoking), and perceived mental health by gender; 2) examine the association between school grades at the end of compulsory school and gambling among men and women aged 1829 in Finland when adjusting for sociodemographic variables, substance use and mental health status.

\section{Method}

\section{Procedure}

The data came from the cross-sectional Finnish Gambling 2015 survey conducted by Statistics Finland [4]. Computer-assisted telephone interviews were conducted between $3 \mathrm{M}$ arch and 8 June
2015. Altogether 7400 persons were randomly selected from the Population Information Register. Participants had to be aged 15 to 74 years, have Finnish or Swedish as their mother tongue, and reside in mainland $\mathrm{F}$ inland. In the gross sample, 103 people did not meet these criteria. Overall 4515 interviews were completed, with a $62 \%$ response rate [4]. Register data were linked with the Finnish $\mathrm{G}$ ambling 2015 data. T he data were weighted based on age, gender, and region of residence.

Weekly gambling

Gambling frequency was measured based on participation in 18 different forms of gambling during the past 12 months. F requency was defined based on the type of game that occurred most often and recoded into two categories: 1) gambling weekly, and 2) gambling less often than weekly. We were interested in weekly gambling, because it is usually linked with disordered gambling [8] and other problem behaviours [14]. Those who participated on a weekly basis in lottery games only $(n=48)$ were excluded because playing lotteries is generally viewed as a safe activity with little risk of harm [19]. L ottery is the most popular form of gambling in Finland [4].

\section{A t-risk and problem gambling}

ARPG was defined using the Problem Gambling Severity Index (PGSI), a nine-item instrument measuring past-year gambling behaviour and gambling consequences. All items have four response options ranging from never ( 0 points) to almost always ( 3 points), giving a maximum score of 27 points [20]. As in previous studies $[6,21]$, respondents scoring one point or more were considered ARPG ers. This conflicts with the common PGSI cut-off recommendations for problem gambling, [20] which we were unable to follow due to the small number of people with high gambling severity. $C$ ronbach s alpha for the PGSI among men was 0.86 and among women 0.77 .

\section{Compulsory school achievement}

Final school grades (range 5 10) were derived from Statistics F inland sources. In the F innish school system, the final GPA is reported separately for all subjects and theoretical subjects. In this study, only the grades of theoretical subjects were taken into account due to relatively large number of missing G PA values for all subjects. The grade/grade average represents the categories creditable ( 910$)$, satisfactory ( $\left.\begin{array}{ll}7 & 8\end{array}\right)$, and passable (5 6). Grade 5 is the lowest passing grade, and the data only covered grades 5 or higher. 
The grade average was divided into three classes based on the formal GPA categories mentioned above with 5.176 .49 representing low (passable), 6.508 .44 average (satisfactory) and 8.4510 high (creditable). In Finland, compulsory school education ends at age 16.

\section{Sociodemographics}

The sociodemographic variables were age, income and labour-market status. With the exception of labour-market status, these were based on register data. The income variable was formed by adding together earned income, social security benefits (also included student allowance) and capital income. Income was divided into three categories, with the second and third quartiles combined into one category. Income categories were formed separately for men and women because of the gender differences in annual earnings [12]. For men, the annual income categories were low ( 0 3832), average ( 3833 27,308) and high ( 27,309 96,883); and for women, low ( 0 6387), average ( 6388 22,646) and high ( $22,647 \quad 65,017)$. Responses to the question concerning current labour-market status were recoded as: 1) employed (including employees, farmers and the self-employed), 2) students and 3) not in employment, education or training (NEET). The NEET category included unemployed respondents, conscripts or persons undergoing non-military service, persons caring for a child (also included those who were temporarily on parental leave) or relative at home, or homemakers or other.

\section{Substance use}

Alcohol consumption was measured with the threeitem Alcohol U se Disorders Identification Test/ Consumption (AUDIT-C) [22]. Scores of at least 6 (for men) and at least 5 (for women) indicated risky alcohol consumption [23]. C ronbach s al pha for men was 0.52 and for women 0.63 . Smoking was measured with the question $\mathrm{H}$ ave you smoked during the past 12 months?, with three response options: yes, daily, yes, occasionally and no. Respondents in the first category were considered daily smokers.

\section{Perceived mental health}

Perceived mental health was measured with the fiveitem M ental H ealth Inventory ( M H I-5) [24], which enquires about feelings of nervousness, calmness, happiness, and feeling down and gloomy during the past four weeks. Sum scores were scaled to a range of 0 100, with high scores indicating good perceived mental health [24]. In this study a cut-off score of 60 was used to indicate moderate to poor mental health [25]. Cronbach s alpha for men was 0.75 and for women 0.84 .

\section{D ata analysis}

$D$ ifferences between men and women in weekly gambling, ARPG, daily smoking, risky alcohol use, and perceived mental health were first compared using the chi-square test. The same correlates were then examined by men s and women s final school grades, again using the chi-square test. T he $95 \%$ confidence intervals (CIs) were estimated for all prevalence rates. Finally, gender stratified logistic regression models adjusted for sociodemographic variables, substance use, and perceived mental health were conducted for both weekly gambling and AR PG. The results of the regression analyses are presented as odds ratios (ORs) and their corresponding $\mathrm{CI}$ s. The analysis was done using SPSS version 24 .

\section{Results}

The mean age of the participants was 23.3 years (SD 3.4). Just over half of them (51.5\%) were men. $M$ en $S$ average annual income was 16,153.6 (SD 14,514.2), women s 14,721.4 (SD 10,737.8). Just under half $(47.6 \%)$ of the respondents were employed, $37.4 \%$ students and $15.1 \%$ unemployed. Overall, women had higher final compulsory school grades than men $\left(\chi^{2}(1)=38.4, p<0.001\right)$, with $37.7 \%$ belonging to the highest grade category and $7.2 \%$ to the lowest. A mong men $21.9 \%$ had high and $18.7 \%$ low grades.

Weekly gambling and ARPG were more common among men than women. ARPG occurred among $27.5 \%$ of men, and $32.5 \%$ of men were considered weekly gamblers. The corresponding figures for women were $12.0 \%$ and $12.1 \%$.

ARPG and weekly gambling were less common among women with higher final school grades compared with those with average and low final school grades (See Table I). Among men, by contrast, those with low, average and high final school grades differed only in the frequency of weekly gambling (SeeTable I).

As is seen in Table II (model 2), weekly gambling was linked to smoking (OR: $2.1,95 \% \mathrm{Cl}: 1.3$ 3.6) and risky alcohol use (OR: $2.1,95 \% \mathrm{Cl}: 1.23 .4$ ) among men and smoking among women (OR: 3.7, $95 \% \mathrm{Cl}: 1.5$ 8.9). H owever, weekly gambling was not associated with moderate/poor mental health among men and women in model 3 or 4 . In model 1 , low final school grades were associated with weekly gambling among both women (OR: 4.7, 95\% Cl: 1.1 19.1) and 


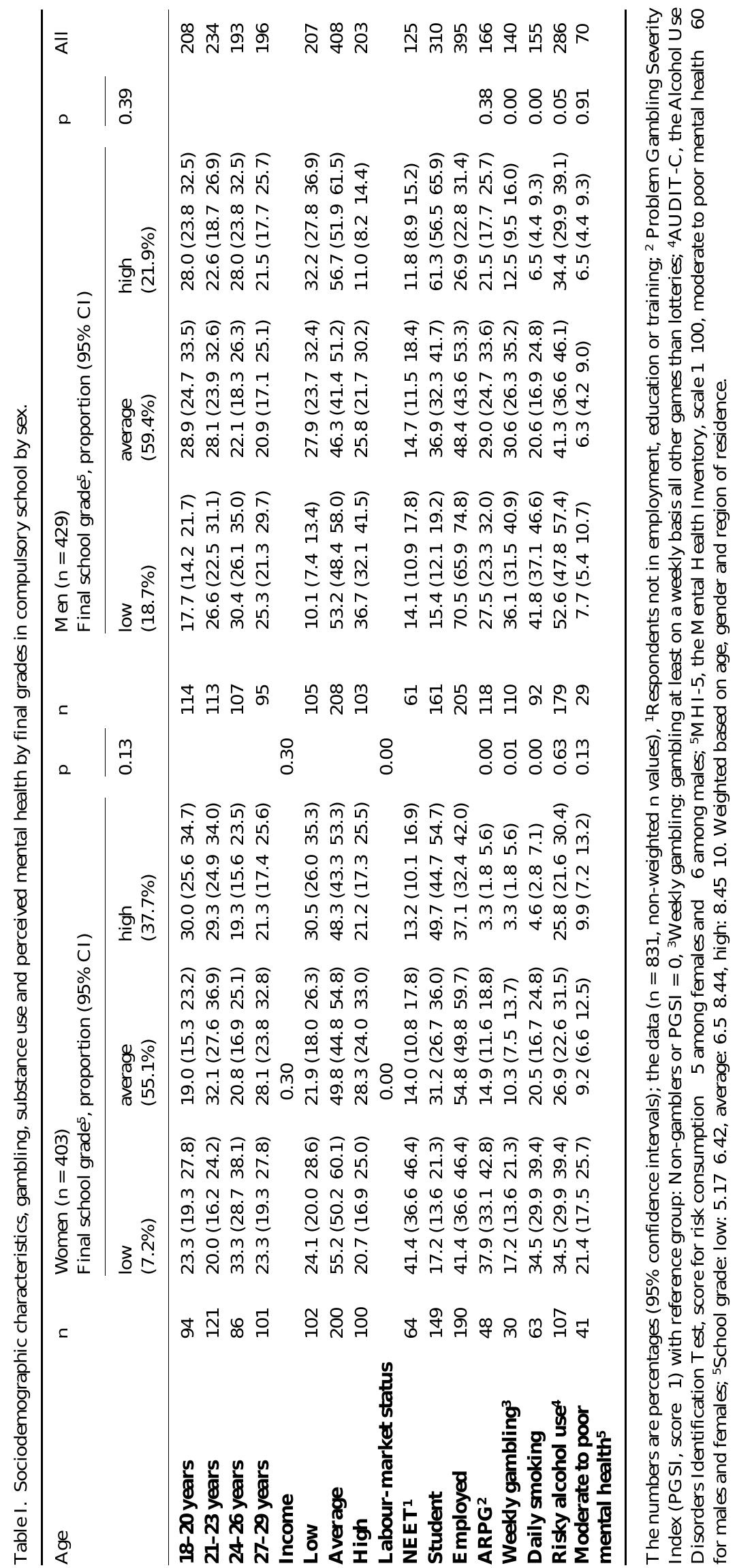


men (OR: 3.6, 95\% CI: 1.5 8.7), when adjusted for sociodemographic factors. On the other hand, low and average final school grades were no longer statistically significantly associated with weekly gambling among women when substance use was adjusted for in model 2 and in model 4 . H owever, among men low and average final school grades remained significantly associated with weekly gambling even when adjusting for all variables (SeeTable II).

InTable III, ARPG was linked to risky alcohol use among men (OR: 1.8, 95\% Cl: 1.12 .8 ), but not among women in model 2 . In models 3 and 4, ARPG was associated with moderate/poor mental health among both men (OR: $2.7,95 \% \mathrm{Cl}: 1.26 .1$ ) and women (OR: $2.6,95 \% \mathrm{Cl}: 1.1$ 6.2). Among women, low final school grades were associated with ARPG (OR: 14.8, Cl: 4.152 .6 ) when all potential confounders were adjusted for in model 4 . Among men, final school grades were not associated with ARPG (SeeTable III).

\section{Discussion}

Our results showed that low and average final school grades at age 16 were associated with both weekly gambling and ARPG later in life. This is in line with earlier findings $[15,18]$. We also observed notable gender differences.

A larger proportion of men than women gambled weekly and were ARPG ers [26]. M en also had lower GPAs in compulsory school than women, as has been shown earlier [16]. Furthermore, our results showed that low final school grades and alcohol use were associated among men who were considered weekly gamblers or ARPG ers, while alcohol use seemed to confound the association between final school grades and weekly gambling for women. Smoking and final school grades, on the other hand, were associated among both men and women who were weekly gamblers. An association between moderate or poor mental health and final school grades was only seen for A R PG ers. An earlier study in Sweden found an association between poor mental health, final school grades and moderate/severe problem gambling only for women [17]. Our results indicate that poorer school achievement may lead to less favourable life paths. These gender differences should be reflected in prevention and treatment programmes.

Among men, low and average final school grades were associated with weekly gambling even when controlling for sociodemographic factors, substance use and mental health. Among women, low and average final school grades were associated with weekly gambling only in models that did not adjust for substance use. Overall, our results indicate that lower final school grades at age 16 predict regular (i.e. weekly) gambling later in life. For young Finnish women, it is possible that risky alcohol use is a distinct risk behaviour that is not associated with gambling. O ur findings are consistent with results from Sweden where a positive association was found between alcohol use and gambling among males, whereas the association was reversed for females [15].

We also found a clearer association between lower final school grades and problematic gambling later in life among women than among men another result consistent with earlier findings from Sweden [17]. Among women ARPG was associated with low and average final school grades in all models. It is known that women $\mathrm{s}$ motives for gambling differ from men $\mathrm{s}$ and often have to do with escape, boredom or loneliness [27]. It is possible that lower final school grades may lead to an undesirable path in life, and a lower socioeconomic status, which in turn may fuel increased spending on gambling [13]. G ambling may become a harmful coping style later in life especially for women. This highlights the importance of educating the public about the randomness of specific game types in prevention programmes.

Another potential explanation for women s vulnerability to problematic gambling is that gambling has become increasingly accessible for women over the years and greater numbers of them are now gambling. At the same time there is still a stigma around gambling particularly evident among females [9].

\section{Study limitations}

K ey strengths of this study include its nationally representative sample with a higher than average response rate (62\%) [28]. In addition, the use of population weights reduced bias to non-response. Selective non-response may nonetheless have affected the association between final school grades and gambling. The instruments we used also involved some limitations. Cronbach s alpha for risky alcohol use among men was relatively low at 0.52 . T he choice of the PGSI cut-off score for ARPG may also have influenced the results, although the cut-off score of one or more scores has been previously used $[6,21]$. A recently published review identified several challenges in evaluating the burden of harms among ARPGers, including misclassification of low-risk gamblers, underestimating impacts of the binary classification to high-risk populations, a tendency to confuse behaviour and harm as well as the use of potentially overly inclusive definitions of harm among low-risk gamblers [28]. Additionally, we are unable to draw any conclusions on the causalities between correlating variables. Also, the time order between 


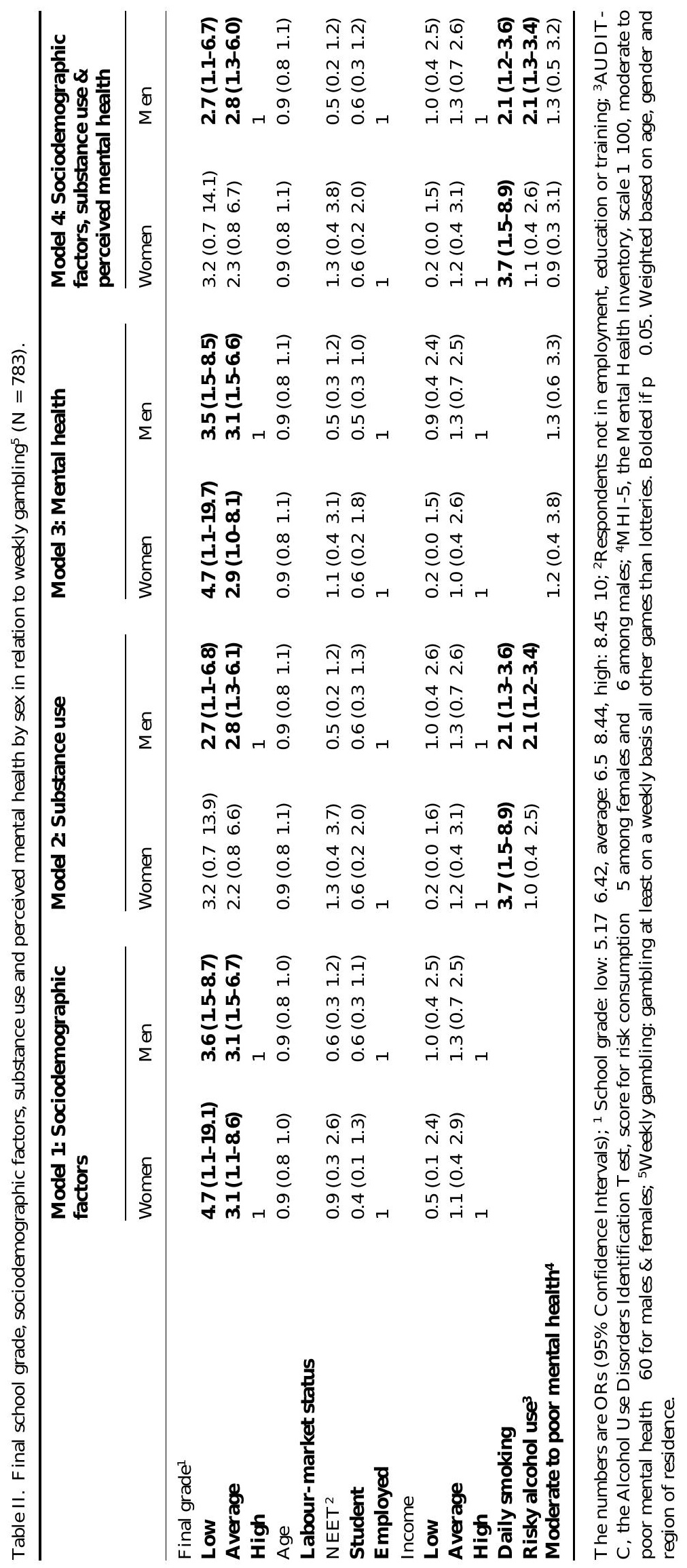




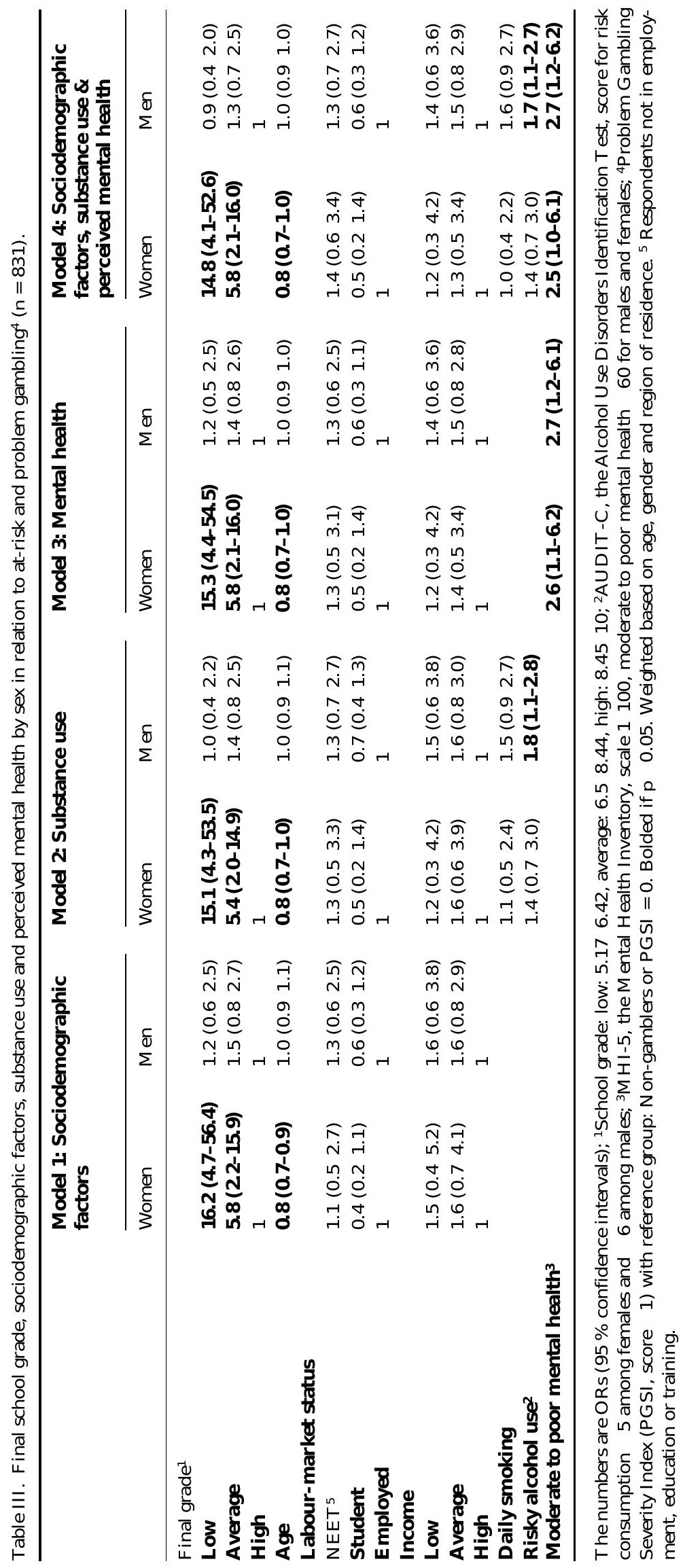


gambling, substance use and mental health was unclear, due to lacking information about the onset of these behaviours. Hence, it would be fruitful to design a study that has an accurate baseline measure as well.

R egardless of these limitations, our study demonstrated that early adulthood often involves many risktaking behaviours, including gambling. L ower final school grades may be linked with gambling and other risk behaviours later in life. H owever, this claim still needs to be verified with research exploring the longitudinal association between final school grades and problem behaviours. Therefore, studies are also needed to examine the association between school achievement and gambling participation. Further evaluation could also include type of gambling, the nature of the gambling provider (commercial, private, charity, community, non-profit group) and gambling mode (face-to-face, remote) as well as gambling expenditure and time spent gambling [29].

\section{Conclusions}

O ur findings indicate that adolescents with lower final school grades are more likely to gamble weekly later in life. L ower final school grades are also linked with ARPG among women. Earlier research has shown that adolescents gambling is clearly associated with gambling later in life [17]. School teachers are particularly well placed to influence student gambling attitudes and behaviour. It therefore makes sense to formulate clear school policies and implement early prevention programmes. It might also be useful to screen young people for problematic gambling behaviour with a view to addressing gender-specific highrisk behaviours through intervention strategies.

\section{Acknowledgements}

The authors wish to thank their funding sources, the Finnish M inistry of Social Affairs and Health, Finland, and the Finnish Foundation for Alcohol Studies. We also wish to express our gratitude for qualified translator $\mathrm{D}$ avid $\mathrm{K}$ ivinen for revising the language.

The study protocol was approved by the Ethics Committee of the $\mathrm{N}$ ational Institute for $\mathrm{H}$ ealth and Welfare. All potential participants received written information about the study. Participation in the study was voluntary. Permission to use the register data was received from Statistics F inland.

\section{Declaration of conflicting interests}

The authors declare that there is no conflict of interest.

\section{Funding}

The author(s) disclosed receipt of the following financial support for the research, authorship, and/or publication of this article: The M inistry of Social Affairs and $\mathrm{H}$ ealth, Finland, and the Finnish Foundation for Alcohol Studies funded the study (appropriation under section 52 of the L otteries Act). H owever, they had no role in the study design, data analysis or data interpretation or in any phase of the publication process.

\section{References}

[1] D owling N A, M erkouris SS, G reenwood C], et al. Early risk and protective factors for problem gambling: A systematic review and meta-analysis of longitudinal studies. Clin Psychol Rev 2017;51:109 124.

[2] Korn D and Shaffer H. Gambling and the health of the public: Adopting a public health perspective. J Gambl Stud 1999;15:289 365 .

[3] Ekholm O, Eiberg S, Davidsen $M$, et al. The prevalence of problem gambling in Denmark in 2005 and 2010: A sociodemographic and socioeconomic characterization. J Gambl Stud 2014;30:1 10.

[4] Salonen A and Raisamo S. Suomalaisten rahapelaaminen 2015. Rahapelaaminen, rahapeliongelmat ja rahapelaamiseen liittyv $\mathrm{t}$ asenteet ja mielipiteet 15 74-vuotiailla [F innish gambling 2015. Gambling, gambling problems, and attitudes and opinions on gambling among $F$ inns aged 15 74] $\mathrm{N}$ ational Institute for $\mathrm{H}$ ealth and Welfare (THL). Report 16/2015, 2015.

[5] Wisk LE and Weitzman ER. Substance use patterns through early adulthood: Results for youth with and without chronic conditions. A m J Prev M ed 2016;51:33 45.

[6] Browne $M, G$ reer N, Rawat V, et al. A population-level metric for gambling-related harm. Int Gambl Stud 2017; 31:1 14.

[7] H ayatbakhsh MR, Clavarino A, Williams GM, et al. Young adults gambling and its association with mental health and substance use problems. Aust N Z J Public $\mathrm{H}$ ealth 2012;36:160 166.

[8] Castrø S, Basnet S, Salonen AH, et al. Factors associated with disordered gambling in F inland. Subst A buseTreat Prev Policy 2013;8:24.

[9] M cC ormack A, Shorter GW and Griffiths M D. An Empirical study of gender differences in online gambling. J $\mathrm{G}$ amb Stud 2014;30:71 88.

[10] Van der $M$ aas M. Problem gambling, anxiety and poverty: An examination of the relationship between poor mental health and gambling problems across socio-economic status. Int G ambl Stud 2016;16:281 95 .

[11] D avidson T, Rodgers B, M arkham F, et al. G ambling expenditure in the ACT (2014): By level of problem gambling, type of activity, and socioeconomic and demographic characteristics. Final Report, Canberra: Australian National U niversity, 2016.

[12] Statistics Finland. I ncomes and labor cost, http://tilastokeskus. fi/tup/suoluk/suoluk_palkat.html, (2017, accessed $6 \mathrm{M}$ arch 2017).

[13] Edgren R, Castrøn S, Alho H, et al. Gender comparison of online and land-based gamblers from a nationally representative sample: $D$ oes gambling online pose elevated risk? Comput H uman B ehav 2017;72:46 56.

[14] R s nen T, L intonen T and K onu A. G ambling and problem behavior Among 14- to 16-year-old boys and girls in Finland. J G ambl Issues 2015;31:1 22. 
[15] $\mathrm{Fr}$ berg $\mathrm{F}, \mathrm{H}$ allqvist J and Tengstr $\mathrm{mA}$. Psychosocial health and gambling problems among men and women aged 1624 years in the Swedish $\mathrm{N}$ ational Public H ealth Survey. Eur J Public H ealth 2013;23:427 433.

[16] Ristikari $T, T$ rm kangas $L$, L appi $A$, et al. Suomi nuorten kasvuymp rist $\mathrm{n} .25$ ik vuoden seuranta vuonna 1987 Suomessa syntyneist [F inland as a growth environment for young people. 25-year follow up of those born in Finland in 1987]. Terveyden ja hyvinvoinnin laitos (THL) ja N uorisotutkimusverkosto. Raportti 9/2016, 2016.

[17] $\mathrm{Fr}$ berg F, M odin B, Rosendahl IK, et al. The association between compulsory school achievement and problem gambling among Swedish young people. J Adolesc $\mathrm{H}$ ealth 2015;56:420 428 .

[18] Winters KC, Stinchfield RD, Botzet A, et al. A prospective study of youth gambling behaviours. Psychol A ddict B ehav 2002;16:3 9.

[19] C urrie SR, H odgins D C, Wang J, et al. Risk of harm among gamblers in the general population as a function of level of participation in gambling activities. Addiction 2006;101: 570580.

[20] Ferris J and Wynne H. The Canadian Problem Gambling Index: Final Report, Ontario (CAN): the Canadian Centre on Substance Abuse, 2001.

[21] Edgren R, Castrø S, M kel M, et al. Reliability of instruments measuring at-risk and problem gambling among young individuals: A systematic review covering years 2009 2015. J A dolesc $\mathrm{H}$ ealth 2016;58:600 615 .

[22] Bush K, K ivlahan DR, M CD onell M B, et al. T he AU DIT alcohol consumption questions (AUDIT-C): An effective
Compulsory school achievement and gambling

brief screening test for problem drinking. Ambulatory Care Quality Improvement Project (ACQUIP). Alcohol U se Disorders Identification Test. Arch Intern Med 1998;158:1789 1795.

[23] Kaarne $T$, Aalto $M$, Kuokkanen $M$, et al. AUDIT-C, AUDIT-3 and AUDIT-QF in screening risky drinking among Finnish occupational health-care patients. Drug Alcohol Rev 2010;29:563 567.

[24] Veit CT and Ware JE.T he structure of psychological distress and well-being in general populations. J Consult C lin Psychol 1983;51:730 742

[25] Theunissen $M-J$, Jansen $M$ and van $G$ estel $A$. A re mental health and binge drinking associated in Dutch adolescents? Crosssectional public health study. BM C R es N otes 2011;4:100.

[26] Edgren R, Castrøn S, Jokela M, et al. At-risk and problem gambling among $F$ innish youth: T he examination of risky alcohol consumption, tobacco smoking, mental health and Ioneliness as gender-specific correlates. $\mathrm{N}$ ord Stud A Icohol D rugs 2016;33:61 79.

[27] Brown S and C oventry L. Q ueen of hearts:The needs of women with gambling problems. Financial \& Consumer Rights C ouncil, 1997.

[28] Delfabbro $P$ and $K$ ing $D$. Prevention paradox logic and problem gambling: $\mathrm{D}$ oes low-risk gambling impose a greater burden of harm than high-risk gambling? J B ehav Addict 2017;20:1 5.

[29] Williams RJ, Volberg RA, Stevens RM G, et al. The de nition, dimensionalization, and assessment of gambling participation. Report for the Canadian Consortium for Gambling Research, 1 February 2017. 